\section{PCR Detection of Microbial Pathogens}

\author{
Mark Wilks, Editor
}

Humana Press, New York,
New York, USA, 2012
ISBN-10: 1603273522
ISBN-13: 978:1603273527
Pages: 328; Price: US $\$ 84.00$

This book covers general challenges of introducing primarily noncommercial PCRs and specific procedures into the laboratory, including sample treatment, extraction protocols, quality and quality assurance, and internal and external laboratory processes. The chapters on specific pathogens illustrate principles that could be applied in many diagnostic laboratories.

The editor's preface to this book is helpful in framing approaches to PCR pathogen detection methods. The focus is primarily on detection of bacterial pathogens, with the exception of Pneumocystis spp., and the case is made for using less expensive noncommercial strategies that enable more flexibility and customization. The book addresses the many parameters of nucleic acid preparation, buffer choice, primer construction, inhibition, cycling parameters, detection, and statistical analysis.

The $\approx 300$ pages of text are divided in 21 chapters, of which the first 3 cover concepts of importance to all clinical laboratories using PCRs. The third chapter, which covers quality and quality assurance, is particularly comprehensive in its treatment of internal and external laboratory process and PCR controls. This chapter covers a variety of concepts, from Westguard rules for investigations of systematic and other errors, to proficiency testing, and includes many useful tables. Of importance to clinical laboratories and epidemiologic investigations alike, the authors make an essential point that up to $75 \%$ of errors in the testing process can be attributed to improper sample collection and transport of specimens, areas that often get less attention than assay quality control. The fourth chapter covers preanalytical and extraction protocols specifically for molecular detection of pathogens in whole blood, which is a particularly challenging specimen.

The remaining chapters cover a mixture of mostly real-time and some conventional PCRs targeting specific pathogens (sometimes by multiplex approaches), and 1 chapter describes a loop-mediated isothermal amplification method for detection of Campylobacter spp. The pathogens and techniques covered represent a good survey of approaches and vendor equipment choices. The quality of the chapters in this book varies widely, and some repetitive information is included. Overall, this book would be of interest to those involved in PCR principles and laboratory quality control. It contains examples of successful noncommercial diagnostic PCRs. If your pathogen(s) of interest are covered, it is an added bonus.

\section{Deborah F. Talkington}

Author affiliation: Centers for Disease Control and Prevention, Atlanta, Georgia, USA

DOI: http://dx.doi.org/10.3201/eid1908.130528

Address for correspondence: Deborah F. Talkington, Centers for Disease Control and Prevention, 1600 Clifton Rd NE, Mailstop C03, Atlanta, GA 30033, USA; email: dft1@cdc.gov

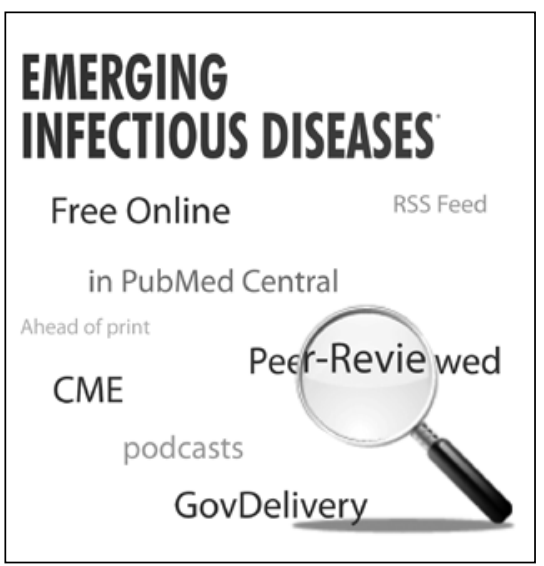

\section{Real-time PCR in Food Science: Current Technology and Applications}

\author{
David Rodríguez-Lázaro, editor
}

\section{Caister Academic Press/ \\ Horizon Scientific Press, \\ Poole, United Kingdom, 2013 \\ ISBN-10: 1908230150 \\ ISBN-13: 978-1908230157 \\ Pages: 302; Price: US $\$ 319.00$}

This 302-page book describes methodologies and applications of real-time PCR in food science. In addition to detection of enteric pathogens, including foodborne and waterborne parasites, a section on food quality provides information on the use of this method to detect genetically modified organisms, allergens, and animal or plant species in food products. This book will be valuable to food scientists with an interest in real-time PCR, also known as quantitative PCR or qPCR, (not to be confused with reverse transcription PCR, or RT-PCR). This book provides a comprehensive overview of conventional and qPCR methods used to detect pathogens in contaminated foods, as well as their use in analysis of food integrity, including the detection of genetically modified organisms, allergens, and authentication of biological species in labeled foods. The book is divided into 3 sections.

The first section, comprising 4 chapters, provides a detailed examination of basic methodologies of qPCR. The inclusion of an introduction to these methodologies, sample preparations, assay design, and the role of controls is beneficial for new scientists and experienced readers. As a bonus, color plates are included.

The second and third sections span 14 chapters. Each of the chapters covering detection of enteric pathogens is organized similarly, which allows the reader to quickly 